\title{
Superando a falsa dicotomia entre natureza e construção social: o caso dos transtornos mentais
}

Cláudio E. M. Banzato*1

Rafaela Zorzanelli*2

As revisões periódicas das classificações diagnósticas em psiquiatria sempre provocam intensos questionamentos que interrogam sobre a própria natureza dos objetos classificados. A pergunta recorrente é: os transtornos psiquiátricos existem de fato ou são apenas construções sociais? Neste artigo, procuramos esclarecer os pressupostos da posição essencialista e a do construtivismo social, e defender que existem alternativas conceituais, como o modelo dos tipos práticos, que nos permitem retirar o eixo central do debate nosológico da disputa natureza versus construção social.

Palavras-chave: Psiquiatria, nosologia, essencialismo, tipos práticos

${ }^{* 1}$ Universidade Estadual de Campinas - Unicamp (Campinas, SP, Brasil)

${ }^{*}$ Universidade do Estado do Rio de Janeiro - Uerj (Rio de Janeiro, RJ, Brasil) 


\section{OBSERVANDO A PSIQUIATRIA}

O lançamento de cada nova edição de uma classificação diagnóstica em psiquiatria costuma ser acompanhado de muitos questionamentos, que não se limitam aos problemas demarcatórios inerentes a esforços desse tipo, mas que interrogam sobre a própria natureza dos objetos classificados e que, direta ou indiretamente, colocam em xeque a legitimidade médica e social da psiquiatria. Infelizmente, trata-se de um debate que gera mais calor que luz e que se repete quase nos mesmos termos de discussões anteriores, com antagonismos simplificadores e especulares, sem avançar na compreensão do que realmente está em jogo. Raramente se realiza o trabalho paciente e necessário de separar os problemas de diferentes ordens e de inscrevê-los, por assim dizer, num mapa conceitual. Ao se discutir tudo ao mesmo tempo, isto é, ao misturar questões ontológicas, epistemológicas, pragmáticas, sociais e clínicas no mesmo pacote, torna-se complicado, senão impossível, identificar os nós, os pontos críticos de tensão. $\mathrm{O}$ rápido exame da literatura especializada e/ou leiga em torno das classificações psiquiátricas permite a constatação de que uma pergunta é recorrente: os transtornos psiquiátricos existem de fato ou são apenas construções sociais? Em outras palavras, seriam entidades com limites bem definidos biologicamente, às quais a psiquiatria acessaria no ritmo do progresso de seus métodos ou se tratariam de 'constructos sociais', isto é, produtos históricos que, por isso mesmo, nem sempre foram como são, refletindo, em cada período e local, os valores e normas em uso para o que se define como normal e patológico? Tal indagação nos parece bastante reveladora do enquadre conceitual de fundo desse debate. Daí nossa opção por abordar neste artigo inaugural um único tópico que nos parece de importância fundamental e que incide de maneira decisiva na formulação de inúmeras questões nosológicas interligadas: a que tipos, classes, ou espécies de objetos, afinal, correspondem os transtornos mentais? 
Pretendemos explorar, no caso específico dos transtornos mentais, os sentidos dessa contraposição reiterada entre duas posições opostas e simétricas que, no entanto, compartilham os mesmos pressupostos: a de que eles correspondem ou deveriam corresponder no futuro a tipos naturais (entidades bem delimitadas que existiriam como tais na natureza, independentes de nossos recortes) e a de que eles seriam antes (e não poderiam jamais deixar de sê-lo) tipos artificiais (isto é, construções humanas arbitrárias). Não é difícil entrever que aí existe um ideal em operação. O recurso usual à comparação dos transtornos mentais com doenças médicas cujas bases fisiopatológicas já foram elucidadas mostra que nesse ideal hierárquico de modos de ser confluem as expectativas de existência dada e objetividade. Tais atributos seriam hipoteticamente assegurados pela própria existência natural e, portanto, independentes dos esquemas conceituais humanos. Durante a exposição dos meandros dessas duas posições, buscaremos demonstrar que ambas falham em capturar aspectos da maior importância para a conceitualização dos transtornos mentais. O fio condutor da argumentação, portanto, é a tentativa de mostrar que a referida contraposição não apenas não é inevitável, mas que existem alternativas conceituais mais sofisticadas que fazem mais justiça à complexidade dos objetos em questão e que a tornam ociosa.

\section{Transtornos mentais como tipos naturais}

Numa perspectiva realista de senso comum, o conhecimento da natureza equivaleria, em certa medida, à identificação das partições de seus componentes (partículas, matérias, substâncias, organismos) feitas pela própria natureza e não pelos recortes humanos, e ao desvelamento das redes de leis causais vigentes. As classificações humanas, a seu turno, buscariam refletir com precisão tais partições, nomeando e ordenando os diferentes grupos naturais, segundo a essência de cada um. Tal essência estaria inscrita na própria natureza e nós deveríamos procurar reconhecê-la como um conjunto de condições necessárias e suficientes que definiriam o pertencimento a um dado tipo e que, ademais, explicaria o surgimento de outras características relacionadas a esse tipo, além de predizer seu comportamento em certas circunstâncias. Como a natureza disporia seus componentes de uma forma determinada, haveria apenas uma única classificação correta: aquela que espelhasse com perfeição a natureza como ela realmente é ou, em outros termos, que capturasse a taxonomia de sua estrutura íntima. Utilizando a antiga metáfora platônica, diríamos que apenas a classificação correta 'dissecaria a natureza em suas juntas'.

Essa ideia de que a natureza, à semelhança do sistema esquelético de organismos vertebrados, tem 'juntas' implicaria não apenas a existência de 


\section{OBSERVANDO A PSIQUIATRIA}

descontinuidades regulares, que seriam os pontos naturais de clivagem, mas principalmente sua fixidez, determinada de uma vez por todas na origem. Assim, tudo se torna mais fácil quando as linhas de formação são respeitadas. Evitar-se-ia, desse modo, a ingrata tarefa de serrar ossos, que, além de trabalhosa, produz partições sempre arbitrárias. Nesse enquadre, caberia à ciência, portanto, descobrir quais seriam tais unidades naturais, os verdadeiros blocos de construção da natureza. O que está implícito nessa posição é o pressuposto de que um tipo natural é algo que realmente existe de forma independente de quaisquer ações e apreensões humanas (e que as nomeações ou classificações são processos quase espontâneos que completariam esse processo de conhecimento ou acesso ao tipo natural). Talvez o exemplo mais eloquente seja o dos elementos químicos (dispostos em uma das classificações científicas mais bem-sucedidas de todos os tempos, a icônica tabela periódica de Mendeleev). O número atômico (número de prótons em seu núcleo) define, por assim dizer, um dado elemento químico e o separa dos demais. Esse número funciona, ao mesmo tempo, como sua essência (da qual suas características químicas nomologicamente decorrem) e seu critério demarcatório (necessário e suficiente). Uma classificação nessas bases tem um alcance preditivo excepcional, sem contar o apelo de sua simplicidade e elegância. Daí, a compreensível tendência de se tomá-la como o padrão contra o qual outras classificações deveriam ser julgadas. Aliás, mais que um padrão, a tabela periódica dos elementos se converteu em um verdadeiro ideal de robustez e precisão, e isso não apenas na investigação científica da natureza.

Dois pontos foram salientados até aqui: a existência de objetos discretos e bem delimitados na natureza (que seriam seus blocos constitutivos) e a expectativa de que as classificações humanas se fundamentem nessas distinções naturais e a de que nossas categorias tenham, em última instância, como referentes, tais blocos constitutivos. Há decerto uma clara relação de dependência do segundo em relação ao primeiro: afinal, não é possível trinchar as 'juntas' se essas não existem. Por outro lado, a inexistência das 'juntas' não nega a realidade dos objetos, apenas seu caráter discreto e distinto. Para usar um exemplo bastante trivial, em alguns países não há o corte de carne conhecido aqui como picanha. Isso não significa que a anatomia do gado, naquelas paragens, seja diversa da nossa. Tal fato não provoca debates metafísicos sobre a realidade da picanha, pois ninguém a toma como tipo natural, tampouco como 'construção social'. Trata-se de uma realidade evidentemente produzida no encontro com os interesses humanos, nem por isso menos real, como bem o sabem os frequentadores de nossas churrascarias. É nesse contexto que devemos indicar, de passagem, alguns esforços classificatórios notáveis nos reinos da natureza antes de voltarmos nossa atenção para a questão das doenças em medicina, em geral, e dos transtornos mentais em psiquiatria, em particular. 
Linnaeus, no século XVIII, elaborou um 'sistema de natureza' que teve um impacto profundo e duradouro. Em seu sistema, cada um dos três reinos vegetal, animal e mineral era disposto hierarquicamente por ordem, classe, gênero e espécie. O sucesso de sua classificação, no entanto, não foi similar nos três casos. Desde o princípio, o sistema funcionava muito melhor com os seres vivos do que com os minerais. E a razão disso ficaria clara apenas depois de Darwin: a ordenação de Linnaeus dependia em larga medida de haver algum tipo de descendência, isto é, para o naturalista inglês as classificações verdadeiras deveriam ser genealógicas (Hacking, 2013). Aliás, com a teoria da evolução de Darwin, as espécies perdem a fixidez e, desde então, o problema da delimitação das espécies biológicas jamais deixou de ser controvertido. De todo modo, a ideia de uma classificação científica da natureza, em conjunto com as regras para a nomeação das instâncias (sistema binomial, que continua em uso), marcaram indelevelmente os esforços que se seguiram, ainda que assentados em bases bem diversas. Fundador da moderna taxonomia científica, Linnaeus não se furtou a classificar também as doenças, publicando seu Genera morborum, em 1763, mesmo ano em que apareceu a Nosologia methodica de Boissier de Sauvages, cuja inspiração botânica teria exercido larga influência, inclusive na psiquiatria, por meio de Phillipe Pinel.

Nas inúmeras classificações médicas que se seguiram, um pressuposto se manteve razoavelmente: a noção de doença como entidade discreta e delimitada na natureza. As doenças seriam, por assim dizer, semelhantes às espécies naturais de plantas e animais, e o desafio da taxonomia médica e científica seria apreendê-las da forma correta. Do mesmo modo que classificações baseadas em manifestações (reações químicas, no caso dos elementos) e aparência (características morfológicas, no caso de animais e plantas) deram lugar a taxonomias organizadas por princípios considerados mais fundamentais (número atômico e genealogia, respectivamente), a expectativa é de que as classificações de doenças fizessem movimento análogo, com a descrição apoiada em sinais e sintomas sendo progressivamente substituída pela etiologia e fisiopatologia. E, de fato, foi isso que aconteceu em larga medida na medicina moderna. A elucidação de causas e mecanismos está na raiz do sucesso terapêutico que tantas vezes se observou na história da medicina. Doenças com manifestações semelhantes e etiopatologias distintas foram devidamente separadas. Ao refinamento diagnóstico, com frequência, se seguiu a melhor especificação terapêutica. Assim, muitas entidades mórbidas se consolidaram e outras desapareceram. E a demonstração do substrato biológico das doenças se tornou o nome do jogo. A delimitação em bases biológicas passou a conferir o valor de um certificado de realidade. Enquanto isso, diante daquelas doenças cujo substrato biológico permanecia elusivo, incluindo aí o grande grupo dos transtornos mentais (com a notável exceção da Paralisia Geral Progressiva de Bayle), acreditava-se de que se tratava apenas de uma questão de tempo e que tal desvelamento fatalmente ocorreria com 


\section{OBSERVANDO A PSIQUIATRIA}

o desenvolvimento de novos métodos e tecnologias de investigação. No caso da psiquiatria, embora os avanços na compreensão dos fatos biológicos tenham ocorrido numa escala significativa, eles não foram suficientes para fornecer as bases de delimitação dos transtornos, tanto em relação com a normalidade como em relação uns aos outros. O plano sintomatológico prevalece ainda hoje nas classificações de transtornos mentais, com a incorporação de inúmeras mudanças de recorte conceitual e de critérios diagnósticos (em geral, depois de grandes controvérsias) a cada rodada de revisão dos sistemas classificatórios.

É interessante constatar que a expectativa legítima de se encontrar os determinantes biológicos dos transtornos mentais tenha se convertido em um argumento de enorme alcance retórico na discussão sobre a realidade desses transtornos tão complexos. É como se a realidade tivesse sido reduzida à dimensão da biologia, operação correlativa da redução do mental ao cerebral (abandonando a linguagem e os domínios simbólico e cultural, prescindindo de noções como as de sentido, intenção, razão, valor). O transtorno é real se, e apenas se, ele puder ser inscrito biologicamente e delimitado por meio de achados fisiopatológicos. Do contrário, estamos diante de um mero candidato, cuja validade ainda está por ser demonstrada, ou de um simples artefato, de uma categoria sem correspondência na natureza. A fórmula que sintetiza essa posição seria: um tipo natural existe de fato, enquanto que um tipo artificial não passa de uma 'construção social'. E é justamente dessa armadilha conceitual que é preciso escapar. Indicaremos como isso é possível mais adiante, depois da apresentação da perspectiva oposta, a construcionista.

\section{Transtornos mentais como constructos sociais}

O pressuposto central da construção social é que, por meio de argumentos históricos, sociológicos, filosóficos, uma noção, conceito ou prática não precisaria ter se transformado inexoravelmente no que se transformou, nem teria um caminho necessário a percorrer. A perspectiva construtivista se opõe ao pressuposto da autoridade moral da natureza (Daston e Vidal, 2004), segundo o qual, a natureza, em diferentes campos do pensamento, aparece como uma autoridade externa, ou como um imperativo alojado no corpo ou no psiquismo, chamada a dividir os limites entre aquilo que é dela e o que é seu outro - ou seja, o que é natural e o que pertence aos valores humanos, à arte, à cultura.

Situar a abordagem construtivista ou construcionista sobre os transtornos mentais requer, para uma melhor compreensão da proposta, que se dê um passo epistemológico para trás, em direção a algumas de suas múltiplas raízes intelectuais. Isso porque o debate acerca da perspectiva construcionista não se aplica apenas 
ao campo dos transtornos mentais, sendo composto de diferentes saberes. Parte deles, vindos da antropologia, com seu célebre e fundamental debate sobre natureza e cultura. Da sociologia, sobretudo a partir da obra de Peter Berger e Thomas Luckmann (1966/1989), The social construction of reality, e do interacionismo simbólico, por meio da noção de carreira moral. Da filosofia, com o amplo debate de base sobre realismo e idealismo. Cada um desses terrenos, com diferentes níveis de argumentação, contribui, em algum grau, para a formulação da perspectiva do 'construtivismo social'.

Entender doenças como construções sociais pode levar a inúmeras interpretações, já que tal ideia não é autoexplicativa, merecendo esclarecimento. Um desses sentidos é o da historicização das categorias ligadas ao campo da saúde e da doença mental, e talvez esteja nele o principal ganho dessa perspectiva. Outro sentido talvez seja sua interpretação mais radical, de que doenças socialmente construídas são fruto de uma sociedade medicalizada, liberal e urbana, e, assim sendo, não existiriam como doenças 'reais', mas como resultado do controle social da psiquiatria pela rotulação e estigmatização dos indivíduos, da ação das indústrias farmacêuticas, interessadas em vender medicamentos, e portanto, em produzir transtornos que não existiriam.

A ideia de que perturbações mentais são construções e não possuem realidade tem a marca indelével - e talvez seu ponto mais extremado - em Thomas Szasz, com sua asserção célebre de que a doença mental é um mito, senão, uma metáfora, desenvolvida, sobretudo, em duas de suas obras: The Myth of Mental Illness (1961/1974) e The Manufacture of Madness (1970/1997). Para Szasz, o conceito de doença física não é problemático, pois a inscrição biológica fornece a garantia do ancoramento factual. No caso da doença mental, no seu entendimento, haveria uma extensão indevida do conceito de 'doença', pois nesse domínio não haveria fatos em jogo, apenas valores. E se viéssemos a ter fatos biológicos, as doenças não seriam mentais ou psiquiátricas, mas sim neurológicas. Trata-se, portanto, de uma posição de princípio.

A figura de Thomas Szasz e suas proposições sobre a doença mental é, portanto, uma referência para a forma mais radical do tema da construção social dos transtornos psiquiátricos, tanto pelo impacto de suas asserções quanto pelo fato de o autor não ter aberto mão de suas ideias até suas últimas obras. Já em The Myth of Mental Illness (1961/1974), ele é enfático ao afirmar que a doença mental não existe, mas somente os problemas da vida. Em artigo homônimo, prévio à publicação do livro, isso aparece em claras palavras: "minha meta neste ensaio é levantar a questão: 'a doença mental existe?' e argumentar que não” (1960, p. 113). Doenças são, para Szasz, alterações patológicas do corpo. Já os transtornos mentais são dificuldades com pensamentos, sentimentos e comportamentos, o que não seriam doenças, mas questões morais ou 'problemas da vida'. Disso, decorreria sua ideia 
central de que a doença mental é, portanto, um mito ou, no máximo, uma metáfora. Desse modo, a linguagem biomédica, e nesse caso, as classificações psiquiátricas não serviriam para enquadrar problemas dessa ordem.

Há um pressuposto basal nas asserções de Szasz de que o padrão ouro para o que se considera doença é a lesão objetivamente identificável, anatômica ou físiológica. Pela ausência desses marcadores, em grande parte dos transtornos mentais até agora estudados, não haveria necessidade do envolvimento médico, como no caso da loucura e de outras formas de sofrimento mental. Um desdobramento dessa posição do autor é um dualismo inconciliável entre doença física e mental, que nos conduz a pressupor que não haja, por exemplo, substratos fisiopatológicos para nenhuma condição mental, ainda que elas não sejam exclusivamente determinantes do quadro clínico. Há, portanto, um não diálogo entre doenças do corpo, que pertenceriam ao campo médico, e problemas da vida, que pertenceriam ao campo das psicoterapias e afins. Seguindo a lógica desse construtivismo radical, não se admitiria, portanto, que formas de doença e sofrimento mental possam ter um substrato fisiopatológico, e que sejam, ao mesmo tempo, produtos de um contexto sócio-histórico - ou seja, que tais manifestações sejam corporificadas (embodied) em um aparato orgânico que lhe oferece condições de possibilidade, e imersas (embedded) em um círculo de valores e em uma cosmologia. As experiências de sofrimento, infortúnios, ou mesmo sintomas mais severos como alucinações visuais ou auditivas parecem, assim, pertencer a um campo ao qual a biomedicina não teria nada a contribuir, a não ser pela rotulação e estigmatização.

Para o autor, se o diagnóstico de 'doença mental' não pode ser verificado por achados anatômicos ou fisiopatológicos, ele só pode ser uma forma de julgamento moral erigido e sustentado pela psiquiatria. Posição de princípio jamais modificada por ele e reiterada em um de seus últimos escritos, "The myth of mental illness: 50 years later" (Szasz, 2011). O autor parece confundir a questão da base biológica de síndromes reconhecidas com a questão de considerá-las doenças ou não. Evidentemente, nem tudo que tem base biológica é doença (exemplos triviais: ser destro ou canhoto, ter cabelos escuros ou loiros). A normatividade do conceito de doença, portanto, não se reduz à biologia.

Caberia então, reformular a dicotomia gerada pelas posições acima descritas, entre transtornos mentais que existem porque apresentam características universais e os que não existiriam porque seriam desdobramentos da ação nefasta e rotuladora da psiquiatria. Talvez nos coubesse perguntar: de que 'existência construída' se trata quando se fala em construção social de doenças?

Hacking (1997) é um dos destacados autores que aponta a tensão entre a noção de que algo é real e a de que algo é construído, resultado do modo pelo qual o real, o construído, tem sido concebidos nas ciências humanas e sociais. A posição de Hacking não aparece aqui sem motivo, já que ele apresenta o ponto 
de vista construtivista, sobretudo tomando como objeto as psicopatologias, para melhor realizar uma crítica às lacunas que essa perspectiva suscita, propondo uma nova semântica - a dos tipos indiferentes e interativos, classificação que adota para superar sua distinção anterior dos tipos naturais e tipos humanos. Os tipos interativos seriam aqueles em torno dos quais as classificações e nomeações produziriam efeitos sobre a autopercepção, havendo um diálogo entre diagnósticos, doença e ideias que delas decorrem (Hacking, 1986, 1995, 1999). O homossexual é um bom exemplo de tipo interativo, delineado no fim do séulo XIX, quando transformado em objeto de teorias médicas, apesar de haver, antes dessa nomeação, o comportamento de relação homoerótica entre pessoas de mesmo sexo. Diferentemente dos tipos indiferentes, teriam capacidade de percepção sobre a classificação que lhes é dada. Os tipos indiferentes, como o próprio nome elucida, não sofreriam a ação daquilo que é dito sobre eles. Talvez possamos extrair da obra do autor, duas proposições centrais que nos auxilie em avançar no debate até aqui referido: 1) A primeira é sua distinção entre objeto e ideia. 2) A segunda é a noção de looping classificatório.

Em relação ao primeiro tema, Hacking se pergunta: "Quando falamos em 'construção social de ' $x$ ', esse ' $x$ ' se refere aos objetos (quarks) ou a ideia e tudo aquilo que ela envolve?” (Hacking, 1997). O autor é certeiro: quando dizemos que algo é socialmente construído pretende-se dizer que o objeto ou a atividade de que se trata tem lugar em um dado cenário social e histórico. Ou seja, o ponto central é a ideia que fazemos sobre aquela atividade, prática ou objeto, nossos modos de conceitualizar o que as pessoas fazem ou falam a respeito delas. Por isso, se se fala em construção social da anorexia ou da genialidade, só se pode estar referindo à ideia ou aos indivíduos classificados sob essa ideia, ou à interação entre essa ideia e outros indivíduos e instituições. Hacking (1997) comenta: “Quando escrevi que o abuso infantil é tanto socialmente construído quanto real, eu pude evitar qualquer contradição por meio de uma pequena distinção: a ideia de abuso infantil e suas consequências materiais podem ser construídas socialmente, mas o abuso infantil é real".

A segunda noção, como adiantamos, é a de looping classificatório dos tipos interativos. Haveria um duplo arco no efeito de retroação referido: o primeiro, incidindo sobre como as classificações científicas influenciam o sujeito classificado; o segundo, sobre como os que são classificados modificam os sistemas de classificação.

\section{Transtornos mentais como tipos práticos}

O debate anterior gira antes em torno da noção de essência dos transtornos do que da existência ou não desses: num caso, os tipos ('naturais') seriam (ao menos, no horizonte) independentes das práticas classificatórias humanas e, no outro, os 


\section{OBSERVANDO A PSIQUIATRIA}

tipos ('construídos') não seriam separáveis das redes sociais e culturas em que estão imersos. O problema é que a posição essencialista é frequentemente tomada como sendo a única alternativa realista, sobretudo quando confrontada com as versões mais radicais do construcionismo social. Se os limites não são claros e as fronteiras são borradas, então a existência do transtorno é colocada em questão. Ora, é possível ser realista sem ser essencialista. E é precisamente isso que pretendemos demonstrar com a breve apresentação da noção de tipos práticos, proposta por Peter Zachar (2000a, 2000b).

A visão de tipos práticos, comprometida com o instrumentalismo científico, passa ao largo da questão 'natureza x construção social', enfatizando o inevitável encontro entre natureza e interesses humanos. $\mathrm{O}$ mundo é recortado em função desses interesses e nenhum recorte vale de forma absoluta para todos os propósitos. Um tipo prático é, portanto, um padrão estável que pode ser identificado com certa confiabilidade e validade. Seu caráter antiessencialista se coaduna com a visão científica do mundo, pois a realidade é sempre mais complexa do que o que nossas categorias conseguem capturar. Se uma descrição de transtorno nos permite operar na realidade clínica, prever comportamentos, fazer prognósticos e integrar tal categoria em teorias científicas que possam ser testadas, é isso que importa. Nessa perspectiva pragmática, o adjetivo 'real' nada acrescentaria a tal descrição de transtorno.

Recusar a visão de transtornos mentais como tipos naturais não significa negar suas bases biológicas e aceitar a tese construcionista radical, mas tão somente defender que tais transtornos não são categorias delimitadas, com condições internas necessárias e suficientes para seu diagnóstico. Por outro lado, reconhecer seus determinantes psicossociais e culturais também não significa que as bases biológicas inexistam. O ponto é outro: qual é o recorte psicopatológico que adotamos, em que contexto, e por que razões? A classificação dos transtornos seria semelhante à organização de uma biblioteca: "Imagine que você herdou uma biblioteca com 20.000 volumes. Você tem que organizá-la. Você poderia classificar os livros pelo autor, cor, tamanho, assunto ou título. Não há uma classificação 'verdadeira' lá fora no mundo esperando para ser descoberta. Existem muitas taxonomias possíveis e diferentes usos possíveis para os quais uma ou outra serão a melhor classificação. A questão se torna não qual é a classificação 'correta' dos livros, mas qual será a mais útil para os nossos propósitos” (Kendler et al., 2011, p. 1145).

O exemplo da biblioteca evidencia que, como os tipos práticos não podem ser inteiramente definidos por propriedades inerentes, critérios externos (relacionais e direcionados pelos interesses humanos) desempenham um papel em sua definição. Tipos práticos teriam limites mais imprecisos que tipos naturais, mas nem por isso eles seriam arbitrários. Diferentes taxonomias teriam graus variados de confiabilidade e utilidade. O que uma classificação de tipos práticos de fato pressupõe é a comparação de critérios que mudam seus valores em diferentes contextos. 
Entendemos que o debate sobre os transtornos mentais e as difíceis decisões sobre as fronteiras com a normalidade e a delimitação dos diferentes transtornos tem muito a ganhar se a disputa sobre 'natureza versus construção social' for posta de lado, ou mais modestamente, se ela ao menos deixar de constituir o centro de gravidade desse debate. Como o modelo dos tipos práticos comprova, existem alternativas conceituais. A realidade dos transtornos mentais não precisa ser defendida de forma essencialista. Convocar a natureza a arbitrar questões de valor, como é sempre o caso, não apenas com os transtornos mentais, mas com as doenças de modo geral, é uma estratégia ingênua e equivocada. Demonstrar a base biológica de uma condição e o seu caráter mórbido são coisas bem distintas.

Invariavelmente, classificamos por nossa conta e risco. E de acordo com nossos múltiplos interesses, nos contextos os mais diversos. Cada classificação tem as suas consequências, que nem sempre são previsíveis de antemão. Quando classificamos pessoas em virtude de seus predicados e infortúnios, estas reagem à forma com que são classificadas e isso pode mudar inclusive a dinâmica de produção e manifestação das próprias características em que se baseiam tais classificações. Assim, não surpreende que as formas de adoecer e os recortes psicopatológicos mudem ao longo do tempo. Parece prudente, portanto, deflacionar a questão sobre a natureza última dos transtornos mentais. Assim, pensamos que conceitualizar os transtornos mentais como tipos práticos e interativos nos permite vislumbrar um pouco melhor o pano de fundo das discussões sobre a nosologia psiquiátrica, deixando-nos mais bem situados para avaliar os prós e os contras das opções nosográficas à nossa disposição - sobretudo no momento de lançamento da quinta edição do DSM e das controvérsias em torno desse fato, que nos convocam a pensar a respeito do tema com clareza e apuro crítico.

\section{Referências}

Berger, P. L., \& Luckman, T. (1989). The Social Construction of Reality: A Treatise in the Sociology of Knowledge. Garden City, NY: Anchor Books. (Trabalho original publicado em 1966).

Daston, L., \& Vidal, F. (2004). The moral authority of nature. The university of Chicago Press: Chicago.

Hacking, I. (1986). Making Up People. In T. Heller, M. Sosna, \& D. Wellberry (eds.). Reconstructing Individualism (pp. 222-236). Stanford, CA: Stanford University Press.

Hacking, I. (1995). The Looping Effects of Human Kinds. In D. Sperber, \& A.J. Premack (eds.). Causal Cognition (pp. 351-383). Oxford: Oxford University Press.

Hacking, I. (1997). Taking Bad Arguments Seriously. London Review of Books, 19(16), 14-16. 


\section{OBSERVANDO A PSIQUIATRIA}

Recuperado em 3 jul. 2013, de <http://www.lrb.co.uk/v19/n16/ian-hacking/taking-badarguments-seriously>.

Hacking, I. (2000). The Social Construction of What. Cambridge, MA: Harvard University Press.

Hacking, I. (2013, Aug.). Lost in the forest. London Review of Books, 35(15), 7-8. Recuperado de: <www.lrb.co.uk/v35/n15/ian-hacking/lost-in-the-forest>.

Kendler, K. S.; Zachar, P., \& Craver, C. (2011). What kinds of things are psychiatric disorders? Psychological Medicine, 41(6), 1143-1150.

Szasz, T. (1960). The Myth of Mental Illness. American Psychologist, 15, 113-118.

Szasz, T. (1974). The Myth of Mental Illness: Foundations of a Theory of Personal Conduct. Harper \& Row. (Trabalho original publicado em 1961).

Szasz, T. (1997). The Manufacture of Madness: A Comparative Study of the Inquisition and the Mental Health Movement. Syracuse, New York: Syracuse University Press. (Trabalho original publicado em 1970).

Szasz, T. (2011). The myth of mental illness: 50 years later. The Psychiatrist, 35(5), 179-182.

Zachar, P. (2000a). Psychiatric disorders are not natural kinds. Philosophy, Psychiatry, \& Psychology, 7(3), 167-182.

Zachar, P. (2000b). Folk taxonomies should not have essences, either: a response to the commentary. Philosophy, Psychiatry, \& Psychology, 7(3), 191-194.

Zachar, P., \& Kendler, K. S. (2007). Psychiatric disorders: a conceptual taxonomy. The American Journal of Psychiatry, 164(4), 557-565.

\section{Resumos}

(Overcoming the false dichotomy between nature and social construction: the case of mental disorders)

The periodic revisions of psychiatric classificatory systems always draw sharp criticism that put at stake the very nature of the objects they classify. The recurrent question is: do psychiatric disorders in fact exist or are they merely socially constructed? In this article, our aim is to clarify the underlying assumptions of both the essentialist and the social constructionist positions. We also show that there are conceptual alternatives, such as the practical-kinds model, that move the center of gravity of the nosological discussion away from the nature-versus-social-construction argument.

Key words: Psychiatry, nosology, essentialism, practical kinds

(Dépasser la fausse dichotomie entre nature et construction sociale: penser autrement les maladies mentales)

Chaque révision des schèmes de classifications en psychiatrie suscite une réflexion accrue à propos de la nature des objets classés. Une question récurrente se 
présente: existent-ils des troubles psychiatriques ou seraient-ils la résultante d'une construction sociale? Dans cet article, nous cherchons à éclairer tantôt les thèses essentialistes, tantôt celles tributaires du constructivisme social. Nous soutenons qu'il y a des alternatives conceptuelles, tel que le modèle des types pratiques, ce qui permet de déplacer l'axe central du débat nosologique de la dispute nature contre construction sociale.

Mots clés: Psychiatrie, nosologie, essentialisme, types pratiques

(Superando la falsa dicotomía entre naturaleza y construcción social: el caso de los trastornos mentales)

Las revisiones periódicas de las clasificaciones diagnósticas en psiquiatría siempre despiertan intensos cuestionamientos sobre la naturaleza de los objetos clasificados. La pregunta recurrente es: ¿los trastornos psiquiátricos realmente existen o son construcciones sociales? En este artículo buscamos establecer los supuestos de la posición esencialista y del construccionismo social, para luego argumentar que existen alternativas conceptuales, como el modelo de los tipos prácticos, que permiten desplazar el eje central del debate nosológico de la oposición naturaleza versus construcción social.

Palabras claves: Psiquiatría, nosología, esencialismo, tipos prácticos

(Die Überwindung der falschen Dichotomie zwischen Natur und sozialer Schaffung: der Fall der Geistesstörungen)

Die periodische Überarbeitung diagnostischer Klassifizierungen in der Psychiatrie führt immer wieder zu intensiven Hinterfragungen, welche die Beschaffung der klassifizierten Objekte selbst hinterfragen. Immer wieder taucht die Frage auf: Gibt es die psychischen Verwirrungen wirklich oder sind es nur soziale Erschaffungen? In diesem Beitrag versuchen wir zu klären, welche die Voraussetzungen der essentialistischen Orientierung und der sozialen Konstrukte sind. Wir vertreten die Stellung, dass es konzeptionelle Alternativen gibt, wie das Modell der praktischen Typen, die uns erlauben, die zentrale Achse der nosologischen Debatte über die Natur versus soziales Konstrukt zu verschieben.

Schlüsselwörter: Psychiatrie, Nosologie, Essentialismus, praktische Typen

Citação/Citation: Banzato, C. E. M., \& Zorzanelli, R. (2014, março). Superando a falsa dicotomia entre natureza e construção social: o caso dos transtornos mentais. Revista Latinoamericana de Psicopatologia Fundamental, 17(1), 100-113.

Editor do artigo/Editor: Prof. Dr. Claudio E. M. Banzato e Profa. Dra. Rafaela Zorzanelli

Recebido/Received: 13.6.2013/6.13.2013 Aceito/Accepted: 20.8.2013/8.20.2013 


\section{OBSERVANDO A PSIQUIATRIA}

Copyright: (C) 2009 Associação Universitária de Pesquisa em Psicopatologia Fundamental/ University Association for Research in Fundamental Psychopathology. Este é um artigo de livre acesso, que permite uso irrestrito, distribuição e reprodução em qualquer meio, desde que o autor e a fonte sejam citados / This is an open-access article, which permits unrestricted use, distribution, and reproduction in any medium, provided the original author and source are credited.

Financiamento/Funding: Os autores declaram não ter sido financiadas ou apoiadas / The authors have no support or funding to report.

Conflito de interesses/Conflict of interest: Os autores declaram que não há conflito de interesses / The authors declare that has no conflict of interest.

\section{Cláudio E. M. Banzato}

Psiquiatra; Doutor em Filosofia; Professor Associado do Departamento de Psicologia Médica e Psiquiatria da Faculdade de Ciências Médicas da Universidade Estadual de Campinas Unicamp (Campinas, SP, Br.).

Av. José Bonifácio, 1856, casa 40

13092-305 Campinas, SP, Br.

e-mail: cbanzato@fcm.unicamp.br / claudio@lexxa.com.br

\section{RAFAela ZoRZANelli}

Psicóloga; Doutora em Saúde Coletiva; Professora Adjunta do Instituto de Medicina Social da Universidade do Estado do Rio de Janeiro - Uerj (Rio de Janeiro, RJ, Br).

Rua Correa Dutra, 16/804

22210-050 Rio de Janeiro, RJ, Br

e-mail: rtzorzanelli@yahoo.com.br / rtzorzanelli@hotmail.com 